\title{
Analysis of integration method in multi-heat-source power generation systems based on finite-time thermodynamics
}

\author{
Hongtao Liu ${ }^{a, b}$, Rongrong Zhaia,*, Kumar Patchigolla ${ }^{\mathrm{b}}$, Peter Turner ${ }^{\mathrm{b}}$, Yongping Yang ${ }^{\mathrm{a}}$ \\ ${ }^{\text {a }}$ Key Laboratory of Condition Monitoring and Control for Power Plant Equipment, Ministry of Education, North \\ China Electric Power University, Beijing 102206, China \\ ${ }^{\mathrm{b}}$ School of Water, Energy and Environment, Cranfield University, Bedford, Bedfordshire MK43 0AL, UK \\ *Corresponding author: Rongrong Zhai \\ E-mail: zhairongrong01@163.com
}

\begin{abstract}
:
Multi-heat-source power generation system is a promising technology to reduce fossil fuel consumption and save investment costs by integrating several heat sources and sharing power equipment components. Researchers have conducted many case studies based on specific power plants to find the preferred integration scheme. However, there is still no unified theory to guide the integration of different energy sources. To explore a common method to integrate various energy sources, this work developed a general multi-heat-source integrated system model based on finite-time thermodynamics, considering the external and internal irreversibility due to the constraint of finite-time and finite-size. The generalised expressions for optimum integration method are explored and expressed in dimensionless parameters. This study indicated the system with two heat-sources performs differently in four regions due to the variation of endothermic temperatures. The characteristics of energy flow and irreversibility reveal that by adding a second heat-source, the first heat-source energy can be substantially reduced at the cost of system efficiency slightly decreasing. Then four application cases for solar-aided coal-fired power plants are conducted to check its feasibility and potential to provide the performance bound of integrating multi-heat-sources.
\end{abstract}

Keywords: Multi-heat-source power generation system; finite-time thermodynamics; general integration method; external irreversibility; internal irreversibility 


\section{Introduction}

In recent years, environmental problems and global warming, caused by the utilisation of fossil fuels have drawn considerable negative attention [1]. The adjustment of the energy structure and development of clean energy is an effective response to alleviating this problem [2]. The multi-heat-source integrated system that combines different energy sources is an important technology to reduce dependence on fossil fuels and improve the contribution of clean energy [3]. Several common multiheat-source thermal power systems are gaining increasing attention, including solar thermal-coal system [4] which is then conceptualised as Solar-Aided Coal-Fired Power Generation (SAPG) [5], biomass-with wither coal or natural gas [6], hybrid nuclear with either solar , biomass, or geothermal energy [7], and various waste heat recovery utilisation systems [8]. In these hybrid systems, power output is more stable and reliable than that in single energy source systems based on intermittent renewable energy. By sharing the power equipment between the different energy sources, the components can be of larger capacity, thereby saving investment costs and higher renewable energy efficiencies may be approached [5]. In this work, SAPG systems are investigated as an example of multi-heat-source integrated systems.

In a SAPG system, solar thermal energy from parabolic troughs or solar tower can be introduced into the different heating stages of a coal-fired power generation system, such as feedwater preheaters, evaporation, superheater, and reheater, as shown in Figure 1. In 1975, Zoschak and Wu first analysed seven different methods to introduce solar 
thermal energy into an $800 \mathrm{MW}_{\mathrm{e}}$ fossil-fueled power plant, including feedwater heating, evaporation, superheating, reheating, air preheating and combined heating [4]. In 2010, $\mathrm{Hu}$ and Yang proposed the SAPG concept and technically demonstrated the advantages in stable operation and greenhouse gas emissions reduction [5]. Later the powerboosting and fuel-saving modes operation modes was investigated in a $200 \mathrm{MW}_{\mathrm{e}} \mathrm{SAPG}$ [9]. Then increasing attention was paid to this integrated system [10].

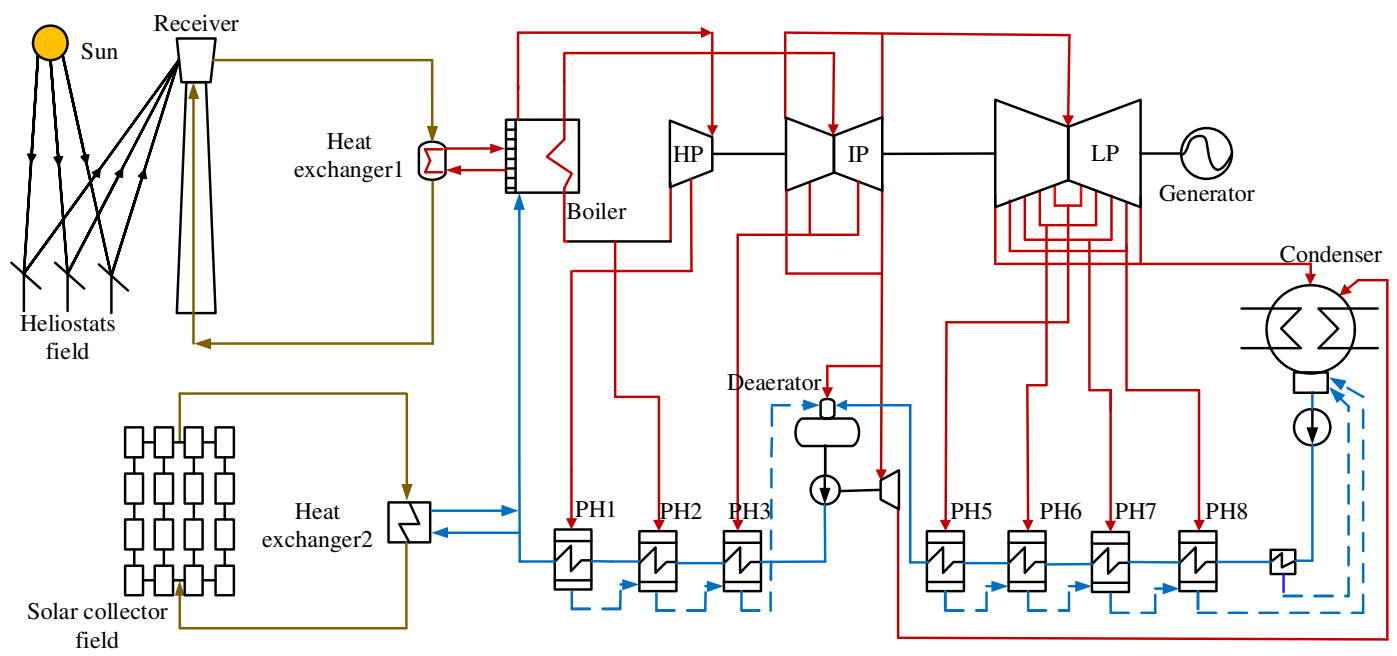

Figure 1. Schematic of a SAPG system

To find the optimum integration scheme of a Solar Parabolic Trough Aided CoalFired Power Generation (SPCG), many researchers performed specific case studies. Popov compared four options using solar thermal energy to replace heat produced by coal fuel to preheat feedwater [11]. Bakos performed a simulation that integrating a 300 $\mathrm{MW}_{\mathrm{e}}$ lignite-fired power plant with different size of parabolic troughs from $30,000 \mathrm{~m}^{2}$ to $120,000 \mathrm{~m}^{2}$ based on TRNSYS software [12]. Rech et al. explored twenty two possible design options to introduce solar thermal energy into a commercial $320 \mathrm{MW}_{\mathrm{e}}$ coal-fired power plant in the fuel-saving mode and considered the high-pressure preheaters as the best integration point [13]. Qin et al. compared the performance of a 
typical $300 \mathrm{MW}_{\mathrm{e}}$ SPCG in four configurations of the solar preheater and three operational strategies [14]. Wu et al. compared an integration scheme in which the firststage extraction steam was replaced by solar thermal energy to preheat feedwater with the scheme in which the third-stage extraction steam was replaced [15]. The scheme that uses parabolic troughs to preheat both feedwater and reheat steam was proposed, indicating an improved overall cycle efficiency and solar-to-electricity efficiency [16]. Wang et al. used eight virtual molten salt heat exchangers to simulate all schemes that integrated the solar energy into the preheaters [17].

For Solar Tower Aided Coal-Fired Power Generation (STPG), solar thermal energy up to $600{ }^{\circ} \mathrm{C}$ can be collected, which can be introduced into boiler for further coal saving and higher solar-to-electricity efficiency. Zhu et al. investigate flexibility of a $1000 \mathrm{MW}_{\mathrm{e}}$ STCG system from exergy viewpoint, in which part of the high-pressure steam at the reheater inlet was heated by a solar-driven salt to water/steam heat exchanger [18]. Zhang et al. compared two commercial $660 \mathrm{MW}_{\mathrm{e}}$ STCG schemes in which solar energy was used to heat superheated steam or sub-cooled feedwater [19]. Then the annual performance with different thermal storage configurations was compared under three different solar load conditions [20]. Li et al. compared the exergy performance of three different STCG schemes in two different operational modes by using Sankey diagrams [21].

In 1824, Carnot proposed the theorem that indicated the upper limit for the efficiency of an engine operating between two thermal reservoirs at a constant temperature [22]. However, this theorem is proposed as applicable to a reversible 
thermal process and its theoretical upper limit efficiency can only be reached if heat transfer is infinitely slow to make the processes reversible. Thus, no such power output/efficiency can be gained from a practical heat engine in finite-time process.

Away from an ideal situation in Carnot theorem, thermal processes in practice need to occur in a finite-time with finite-size devices, and power output must obtain from a heat engine. To find the performance boundary in a system with practical constraints, the maximum output power and the corresponding efficiency of an endo-reversible thermodynamic system with one heat-source in finite-time were first derived by Novikov [23] and Curzon et al. [24], considering the external irreversibility due to the finite-time heat transfer between the working fluid, cold and hot reservoirs. This theory can be used to determine the performance limits in a finite-time, finite-rate and finitesize constrained system and is called finite-time thermodynamics or endo-reversible thermodynamics [25]. Then, to consider internal irreversibility, $\mathrm{Wu}$ and Kiang define the ratio of entropy generation in two isothermal processes as a cycle-irreversibility parameter [26]. The recently same theory has been applied to analyse various practical engines with one heat source. Mousapour et al. applied the same concept to an irreversible Miller cycle to explore the system performance and its influences of design parameters [27]. Nazemzadegan et al. conducted a multi-objective optimisation on a dish-Stirling solar power generation system using finite-time thermodynamic method [28]. Lu et al. applied this method to a lunar-based solar thermal power system and demonstrates its exergy benefits [29]. Yasunaga et al. presented an optimisation on the temperature difference of ocean thermal energy conversion heat engines based on 
finite-time thermodynamic method to achieve the maximum power generation [30].

Most of these studies investigated their own schemes for any one specific individual power plants based on the data availability. However, a general integration theory that can be applied to guide the integration of various multi-heat-source integrated systems has not been studied. This study aimed at developing a generalised multi-heat-source integrated system model based on finite-time thermodynamics rather than comparing any specific individual scheme. The general system was investigated to illustrate the common variation in parameters and in its performance. Later the developed method was applied to four individual SAPG systems to demonstrate the feasibility and potential for application on other multi-heat-source integration systems. The present work is expected to provide a reference about the integration method and performance bound in the development and application of SAPG and other multi-heatsource integration systems.

\section{Multi-heat-source finite-time engine modelling}

In this section, the models of finite-time engine with two or multi-heat-sources are considered, and then the indicators for evaluating thermal performances of this system were evaluated.

\subsection{Two-heat source finite-time engine}

The ideal Carnot cycle comprises two reversible isothermal processes and two reversible adiabatic processes. In this model, each process is assumed at infinitely slow speed to be reversible, and the working fluid can reach the temperature of hot reservoir and cold reservoir. In finite-time thermodynamics, time parameters are introduced to 
represent the time required for a single cycle. As the thermodynamic cycle speeds up, the process deviates from the reversible process due to thermal resistances and the engine starts to deliver power output. In a two-heat-source system, an additional heat source was introduced, in addition to the original heat source, which is usually renewable energy or waste heat from another process. The generalised model of a SAPG is illustrated in Figure 2 as an example.

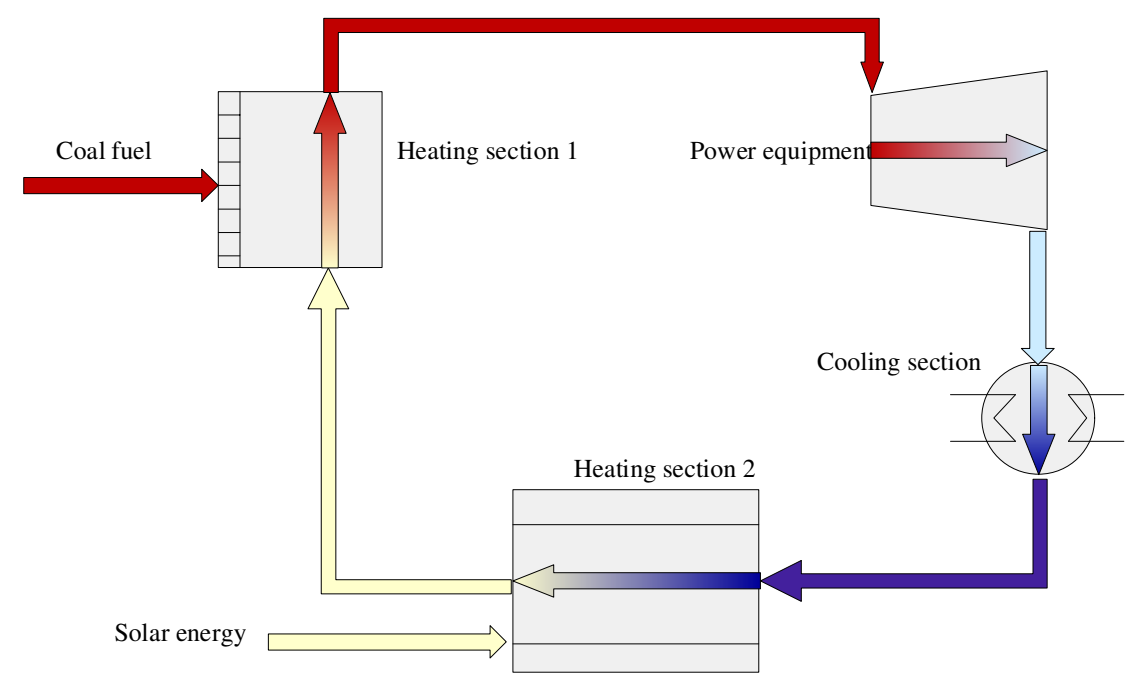

Figure 2. The generalised model of SAPG

The components in a SAPG system are generally classified into the heating section 1 (heated by coal fuel), heating section 2 (heated by solar thermal energy), power equipment (steam turbine), and cooling section (condenser). The temperature in heating section 2 is always lower than the temperature of collected solar energy in actual operations due to the limited time and heat exchanger area. Thereafter, the water/steam is heated by solar thermal energy and coal fuel chemical energy. The thermodynamic processes of a generalised SAPG in finite time is described in a T-S diagram, shown in Figure 3. In this model, the heat source at higher temperature $T_{11}$ is named as the first heat source. The temperature at which the working fluid absorbed heat from this source 
is called the first endothermic temperature $T_{11 w}$. The additional heat source was named as the second heat source, and the temperature at which the working fluid absorbed heat from this source was called the second endothermic temperature $T_{12 w}$. In this process, thermal energy $Q_{12}$ was transferred from the second heat source at $T_{12}$ to the working fluid at $T_{12 w}$ in the period $t_{12}$. Then, the thermal energy $Q_{11}$ was transferred from the first heat source at $T_{11}$ to the working fluid at $T_{11 w}$ in the period $t_{11}$. In this system, due to the external irreversibility in finite-time heat-transfer processes, temperature differences always exist in between the working fluid and the two heat sources, as well as with the cold source. The internal irreversibility is considered, changing the status point 2 to $2_{i r r}, 4$ to $4_{i r r}$ and 6 to $6_{i r r}$.

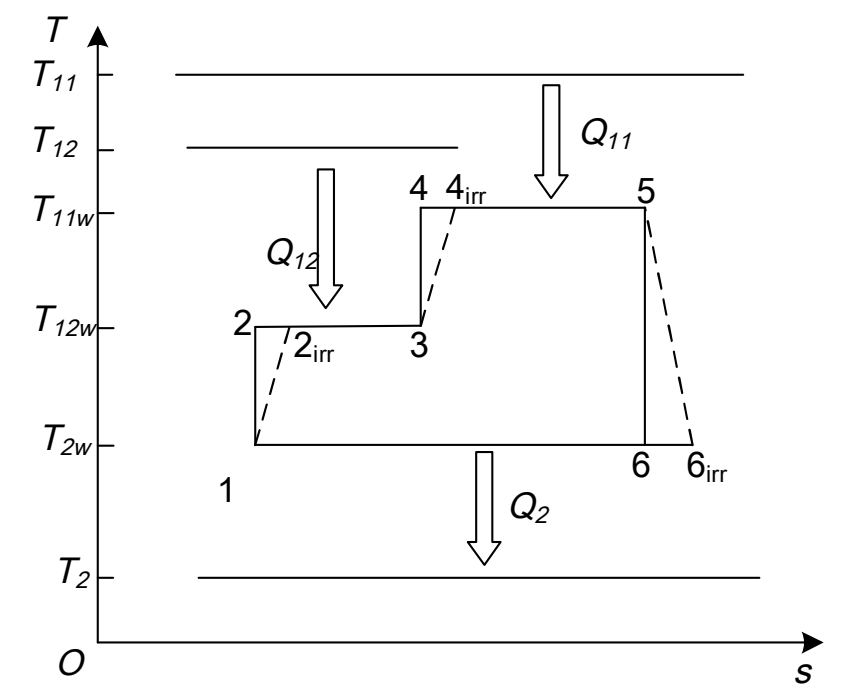

Figure 3. Two-heat-source integrated irreversible heat engine model

The cycle-irreversibility is expressed as:

$$
R=\frac{s_{6_{i r r}}-s_{1}}{s_{5}-s_{4}+s_{3}-s_{2 i r r}}
$$

where $S_{\mathrm{i}}$ is the specific entropy of working fluid at the status point $i$, including points $1-6,2_{\text {irr }}, 4_{\text {irr }}$ and 6 irr.

From the second law of thermodynamics, the entropy generation in the heat 
transfer process satisfies the following equation:

$$
\int_{0}^{t_{2}} \frac{\dot{Q_{2}}}{T_{2 w}} d t=R\left(\int_{0}^{t_{11}} \frac{\dot{Q_{11}}}{T_{11 w}} d t+\int_{0}^{t_{12}} \frac{\dot{Q_{12}}}{T_{12 w}} d t\right)
$$

The heat transfer rates were calculated as follows:

$$
\begin{gathered}
\dot{Q_{11}}=\frac{Q_{11}}{t_{11}}=\alpha_{1}\left(T_{11}^{m_{11}}-T_{11 w}^{m_{11}}\right) \\
\dot{Q_{12}}=\frac{Q_{12}}{t_{12}}=\alpha_{2}\left(T_{12}^{m_{12}}-T_{12 w}^{m_{12}}\right) \\
\dot{Q_{2}}=\frac{Q_{2}}{t_{2}}=\beta\left(T_{2 w}^{m_{2}}-T_{2}^{m_{2}}\right)
\end{gathered}
$$

where $t_{11}, t_{12}$, and $t_{2}$ are the time required for the heat transfer processes. It is assumed that the time required for the engine to complete a cycle is $\gamma\left(t_{11}+t_{12}+t_{2}\right)$, the time required for compression and expansion of the working fluid can be expressed as $(\gamma-1)\left(t_{11}+t_{12}+t_{2}\right)$. With $m_{11}, m_{12}, m_{2}=1$, the expression represents a convection or heat conduction process and $\alpha_{1}=A_{11} k_{11}, \alpha_{2}=A_{12} k_{12}$, and $\beta=$ $A_{2} k_{2}$, representing the heat transfer areas and the total heat transfer coefficients. With $m_{11}, m_{12}, m_{2}=4$, the expression represents a radiative heat transfer process. $\alpha_{1}=$ $\varepsilon_{11} A_{11} \sigma, \alpha_{2}=\varepsilon_{12} A_{12} \sigma$, and $\beta=\varepsilon_{2} A_{2} \sigma$, in which $\sigma$ is the Stefan-Boltzmann coefficient, $5.67 \times 10^{-8} \mathrm{~W} /\left(\mathrm{m}^{2} \cdot \mathrm{K}^{4}\right) ; \varepsilon_{11}, \varepsilon_{12}$, and $\varepsilon_{2}$ are the emittances.

Then the time for a heat transfer process between working fluid and cold source can be expressed as:

$$
t_{2}=\frac{R T_{2 w}\left[\alpha_{1} t_{11} T_{12 w}\left(T_{11}^{m_{11}}-T_{11 w}^{m_{11}}\right)+\alpha_{2} t_{12} T_{11 w}\left(T_{12}^{m_{12}}-T_{12 w}^{m_{12}}\right)\right]}{\beta T_{11 w} T_{12 w}\left(T_{2 w}^{m_{2}}-T_{2}^{m_{2}}\right)}
$$

The power output is calculated by:

$$
\dot{P}=\frac{\dot{Q_{11}} t_{11}+Q_{12} t_{12}-\dot{Q}_{2} t_{2}}{\left(t_{11}+t_{12}+t_{2}\right) \gamma}
$$

If $\tau=t_{12} / t_{11}$ is used to present the time ratio of the two endothermic processes, combining equation (1)-(7), power output can then be written as: 


$$
\dot{P}=\frac{\beta E_{2}\left[\alpha_{1} E_{11}\left(1-R T_{2 w} / T_{11 w}\right)+\alpha_{2} \tau E_{12}\left(1-R T_{2 w} / T_{12 w}\right)\right]}{\gamma\left[R \alpha_{1} E_{11} T_{2 w} / T_{11 w}+R \tau \alpha_{2} E_{12} T_{2 w} / T_{12 w}+(\tau+1) \beta E_{2}\right]}
$$

where $E_{i}=T_{1 i}^{m_{i}}-T_{1 i w}^{m_{i}}, m_{i}=1$ or 4 .

The dimensionless temperature was defined to represent the temperature distribution of the working fluid relative to the highest temperature of the hot reservoir. In this way, the temperature structure of a specific system can be generalized to describe many specific systems with similar temperature structures:

$$
\theta_{i}=\frac{T_{i}}{T_{11}}
$$

For the energy from the second heat reservoir, there is an entry position (the second endothermic temperature, $T_{12 w}$ ) that maximizes the output power. If $T_{12 w}$ is set near to the temperature of the second heat source $T_{12}$ to obtain high efficiency, more time will be required for this second endothermic process, leading to less power output from this energy source. If the second endothermic temperature $T_{12 w}$ approaches the exothermic temperature $T_{2 w}$, the efficiency of the energy from the second heat reservoir will decrease, which also might lead to less power output.

To obtain the highest power output from two given heat sources in finite-time, there is

$$
\begin{gathered}
\text { Objective: } \max \dot{P}\left(T_{11 w}, T_{12 w}, T_{2 w}\right) \\
\text { Constraints: } \quad\left\{\begin{array}{c}
\theta_{2 w} \leq \theta_{11 w} \leq 1 \\
\theta_{2 w} \leq \theta_{12 w} \leq \theta_{12} \\
\theta_{2} \leq \theta_{2 w} \\
\tau, \alpha_{1}, \alpha_{2}, \beta>0
\end{array}\right.
\end{gathered}
$$

With $m_{11}, m_{12}, m_{2}=1$, the positive real solution of the first endothermic temperature for maximum power is solved as:

$$
\frac{T_{11 w, m p}}{T_{11}}=\frac{\alpha_{1} R-\sqrt{\alpha_{1}^{2} R^{2}-R\left[\alpha_{1}+\alpha_{2} \tau\left(\theta_{12}-\theta_{12 w}\right)-\beta(1+\tau)\left(\theta_{2}-\theta_{2 w}\right)\right]\left[\beta(1+\tau)\left(\frac{\theta_{2}}{\theta_{2 w}}-1\right)+R \alpha_{1}-R \alpha_{2} \tau\left(\frac{\theta_{12}}{\theta_{12 w}}-1\right)\right]}}{\beta(1+\tau)\left(\frac{\theta_{2}}{\theta_{2 w}}-1\right)+R \alpha_{1}-R \alpha_{2} \tau\left(\frac{\theta_{12}}{\theta_{12 w}}-1\right)}
$$


The optimum temperature $T_{12 w, m p}$ to maximise the combined effects of efficiency and quantity of introduced energy is:

$$
\frac{T_{12 w, m p}}{T_{12}}=\frac{R \alpha_{2} \tau-\sqrt{\left[\alpha_{2}{ }^{2} \tau^{2} R^{2}-R\left[\frac{\alpha_{1}\left(\theta_{11}-\theta_{11 w}\right)}{\theta_{12}}+\alpha_{2} \tau-\frac{\beta(1+\tau)\left(\theta_{2}-\theta_{2 w}\right)}{\theta_{12}}\right]\left[\beta(1+\tau)\left(\frac{\theta_{2}}{\theta_{2} w}-1\right)+R \alpha_{2} \tau-R \alpha_{1}\left(\frac{\theta_{11}}{\theta_{11 w}}-1\right)\right]\right.}}{\beta(1+\tau)\left(\frac{\theta_{2}}{\theta_{2 w}}-1\right)+R \alpha_{2} \tau-R \alpha_{1}\left(\frac{\theta_{11}}{\theta_{11 w}}-1\right)}
$$

The corresponding exothermic temperature of the working fluid is obtained as:

$$
\frac{T_{2 w, m p}}{T_{2}}=\frac{\beta(1+\tau)+\sqrt{\beta^{2} R(1+\tau)^{2}-\left[\alpha_{2} \tau\left(\frac{\theta_{12}}{\theta_{12 w}}-1\right)+\alpha_{1}\left(\frac{\theta_{11}}{\theta_{11 w}}-1\right)+\beta(1+\tau)\right]\left[\beta R(1+\tau)-\frac{\alpha_{1}\left(\theta_{11}-\theta_{11 w}\right)}{\theta_{2}}-\frac{\alpha_{2} \tau\left(\theta_{12}-\theta_{12 w}\right)}{\theta_{2}}\right]}}{R \alpha_{2} \tau\left(\frac{\theta_{12}}{\theta_{12 w}}-1\right)+R \alpha_{1}\left(\frac{\theta_{11}}{\theta_{11 w}}-1\right)+\beta(1+\tau)}
$$

With other conditions given, any independently optimum temperature can be obtained using the above equations. The temperature distribution in the system at the maximum power can be obtained by simultaneously establishing and iterating Equations (12), (13), and (14). The optimum dimensionless heat absorption temperature at the maximum power was affected by heat transfer characteristic $\alpha / \beta$ and the temperature distribution in the system. Any system has a similar configuration and dimensionless temperature structure has the same dimensionless heat absorption temperature to maximise power output.

\subsection{Multi-heat-source finite-time engine}

With energy introduced from more additional heat sources, the heat sources are numbered as the first, second, third heat source, up to the $n_{t h}$ heat source. The schematic, with additional heat sources in finite time, is shown in Figure 4. 


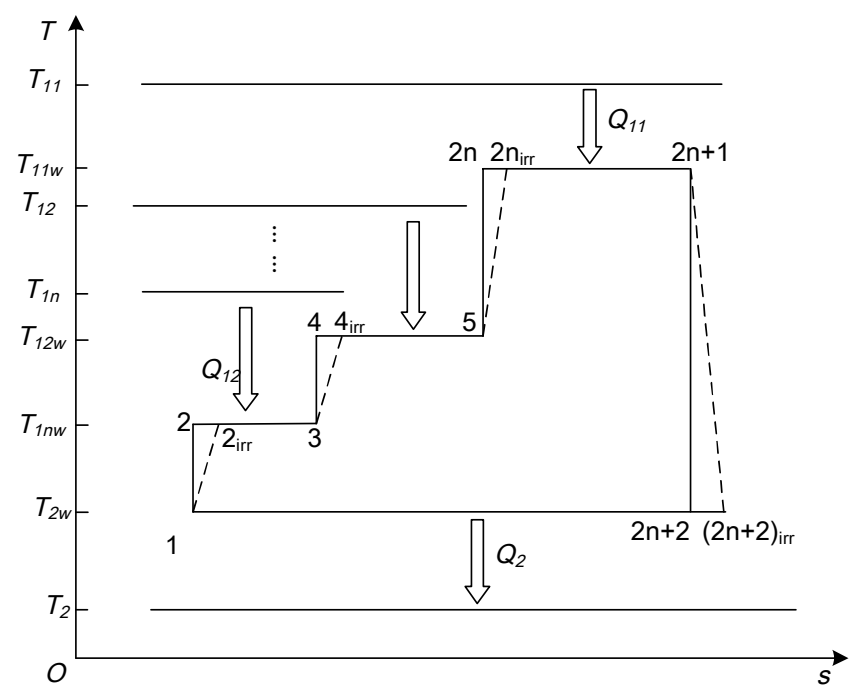

Figure 4. Multi-heat-source integrated heat engine in finite time

The heat transfer rates were calculated as follows:

$$
\begin{aligned}
& \dot{Q_{1 \imath}}=\frac{Q_{1 i}}{t_{1 i}}=\alpha_{i}\left(T_{1 i}^{m_{1 i}}-T_{1 i w}^{m_{1 i}}\right), i=1,2, \cdots, n \\
& \dot{Q_{2}}=\frac{Q_{2}}{t_{2}}=\beta\left(T_{2 w}^{m_{2}}-T_{2}^{m_{2}}\right)
\end{aligned}
$$

The cycle-irreversibility in this system is expressed as:

$$
R=\frac{s_{(2 n+2) i r r}-s_{1}}{\sum_{1}^{n}\left(s_{2 i+1}-s_{2 i_{i r r}}\right)}
$$

From the second law of thermodynamics, the entropy generation in the heat transfer process satisfies the following equation:

$$
\int_{0}^{t_{2}} \frac{\dot{Q_{2}}}{T_{2 w}} d t=R \sum_{1}^{n}\left(\int_{0}^{t_{1 i}} \frac{\dot{Q_{1 l}}}{T_{1 i w}} d t\right)
$$

With $\tau_{1 \mathrm{i}}=t_{1 \mathrm{i}} / t_{11}$ and $\tau_{2}=t_{2} / t_{11}$ used to present the time ratio of the heat transfer processes, the output power can be expressed as:

$$
\dot{P}=\frac{\sum_{1}^{n} \dot{Q}_{1 i} t_{1 i}-\dot{Q_{2}} t_{2}}{\gamma\left(\sum_{1}^{n} \mathrm{t}_{1 \mathrm{i}}+\mathrm{t}_{2}\right)}=\frac{\beta E_{2} \sum_{1}^{n}\left[\alpha_{i} \tau_{1 i} E_{1 i}\left(1-R T_{2 w} / T_{1 i w}\right)\right]}{\gamma\left\{R T_{2 w} \sum_{1}^{n}\left[\left(\alpha_{i} \tau_{1 i} E_{1 i}\right) / T_{1 i w}\right]+\left(\sum_{1}^{n} \tau_{1 i}\right) \beta E_{2}\right\}}
$$

To obtain the maximum power output in this multi-heat-source system for finitetime and finite-size heat transfer, then:

$$
\text { Objective: } \max \dot{P}\left(\mathrm{~T}_{11 \mathrm{w}}, \mathrm{T}_{12 \mathrm{w}} \cdots \mathrm{T}_{1 \mathrm{nw},} \mathrm{T}_{2 \mathrm{w}}\right)
$$




$$
\text { Constraints: } \quad\left\{\begin{array}{c}
\theta_{2 w} \leq \theta_{1(i+1)} \leq \theta_{1 i} \\
\theta_{2 w} \leq \theta_{1 i w} \leq \theta_{1 i} \\
\theta_{2} \leq \theta_{2 w} \\
\tau_{1 i}, \alpha_{1 i}, \beta>0
\end{array}\right.
$$

The positive real solution of the $i_{t h}$ working fluid endothermic temperature at the maximum power can be expressed as:

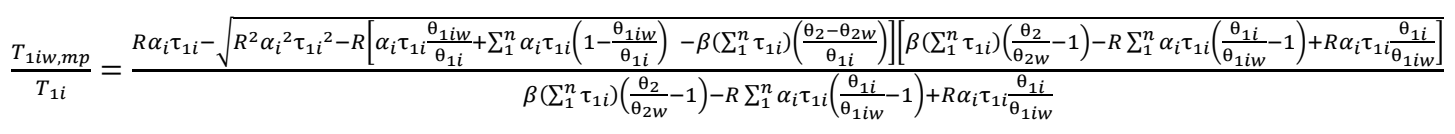

The exothermic temperature of the working fluid at the maximum power can be calculated as:

$$
\frac{T_{2 w, m p}}{T_{2}}=\frac{\beta \sum_{1}^{n} \tau_{1 i}+\sqrt{\beta^{2} R\left(\sum_{1}^{n} \tau_{1 i}\right)^{2}-\left[\sum_{1}^{n} \alpha_{i} \tau_{1 i}\left(\frac{\theta_{1 i}}{\theta_{1 i w}}-1\right)+\beta\left(\sum_{1}^{n} \tau_{1 i}\right)\right]\left[\beta R\left(\sum_{1}^{n} \tau_{1 i}\right)-\sum_{1}^{n} \alpha_{i} \tau_{1 i} \frac{\theta_{1 i}-\theta_{1 i w}}{\theta_{2}}\right]}}{\beta\left(\sum_{1}^{n} \tau_{1 i}\right)+R \sum_{1}^{n} \alpha_{i} \tau_{1 i}\left(\frac{\theta_{1 i}}{\theta_{1 i w}}-1\right)}
$$

Through these equations, the temperature distribution at the maximum output power of the thermodynamic system, with several multiple heat sources, can be obtained. The generalised optimum temperature structure obtained from one system can be applied to any other specific system with similar heat exchange conditions and dimensionless temperature distribution to maximise power output.

\subsection{Thermal performance evaluation criteria}

The energy share is used to represent the energy proportion from a given source:

$$
\lambda_{i}=\frac{Q_{1 i}}{\sum_{1}^{n} Q_{1 i}}=\frac{\alpha_{i} \tau_{1 i} E_{1 i}}{\sum_{1}^{n} \alpha_{i} \tau_{1 i} E_{1 i}}
$$

Dimensionless power is used to represent the ratio of the actual output power to the maximum output power of the system:

$$
\phi=\frac{\dot{P}}{\dot{P}_{\max }}
$$

The thermal efficiency of the system is 


$$
\eta=\frac{\dot{P} \gamma\left(\sum_{1}^{n} \mathrm{t}_{1 i}+\mathrm{t}_{2}\right)}{\sum_{1}^{n} \dot{\mathrm{Q}}_{1 i} \mathrm{t}_{1 i}}=1-\frac{R T_{2 w} \sum_{1}^{n}\left[\alpha_{i} \tau_{1 i} E_{1 i} / T_{1 i w}\right]}{\sum_{1}^{n}\left(\alpha_{i} \tau_{1 i} E_{1 i}\right)}
$$

The multi-heat-source integrated system has two basic operational modes, the fuel-saving mode and the power-boosting mode [31]. In the fuel-saving mode, one heat source is introduced to replace part of thermal load from another heat source to save energy consumption, usually fossil fuel, with its attendant $\mathrm{CO}_{2}$ emissions and fuel costs. The energy-saving rate from one heat source is evaluated to present the fuel-saving effect:

$$
E_{\text {saved }}=\frac{Q_{1}-Q_{11}}{Q_{1}}
$$

where $Q_{1}$ is the power required from the original system, and $Q_{11}$ is the power required from the same heat source in a multi-heat-source integrated system.

In the power-boosting mode, the thermal energy from the original heat source remains constant, while additional heat source energy is introduced. In this operational mode, the working fluid can reach higher temperatures or flow rates. Thus, the system has a higher power output with the same demand from one heat source. The ratio of power increased in power-boosting mode is evaluated as follows:

$$
P_{\text {boosted }}=\frac{P_{1}-P_{0}}{P_{0}}
$$

where $P_{1}$ is the power output of the integrated system in power-boosting mode, $P_{0}$ is the power output in the original system.

\section{Results and discussion}

This section presents the performance characteristics of multi-heat-source thermodynamic systems, the effects of system design parameters and the optimum thermal structure.

\subsection{Validation of the derived expression}


The optimum temperature distribution in the system with a single heat source is calculated by the derived expression. Figure 5 shows the variation of optimum endothermic temperature concerning the cold source temperature. The efficiency, calculated from the obtained temperature distribution, is compared with the efficiency calculated from equation $\eta_{C-A}=1-\sqrt{\frac{T_{2}}{T_{1}}}$ [24]. The efficiency curves derived from an optimum temperature distribution is completely consistent with the reference conclusion. The $1000 \mathrm{MW}$ SPCG system in Zhai et al. [32] was calculated to verify the calculation of multi-heat-source integrated system, as shown in Figure 6. The main parameters of the original power plant and SPCG in two operational modes are shown in Table 1. Table 2 shows the comparison between the calculated results using the expression in the present work and the simulated steam enthalpy drop for power output in the literature. The calculated enthalpy is $0.43 \%$ higher than the result from design data mainly due to the assumption of $R=1$ in the calculation. The difference between the calculation and the simulation in the literature in three cases is $0.21 \%-0.35 \%$.

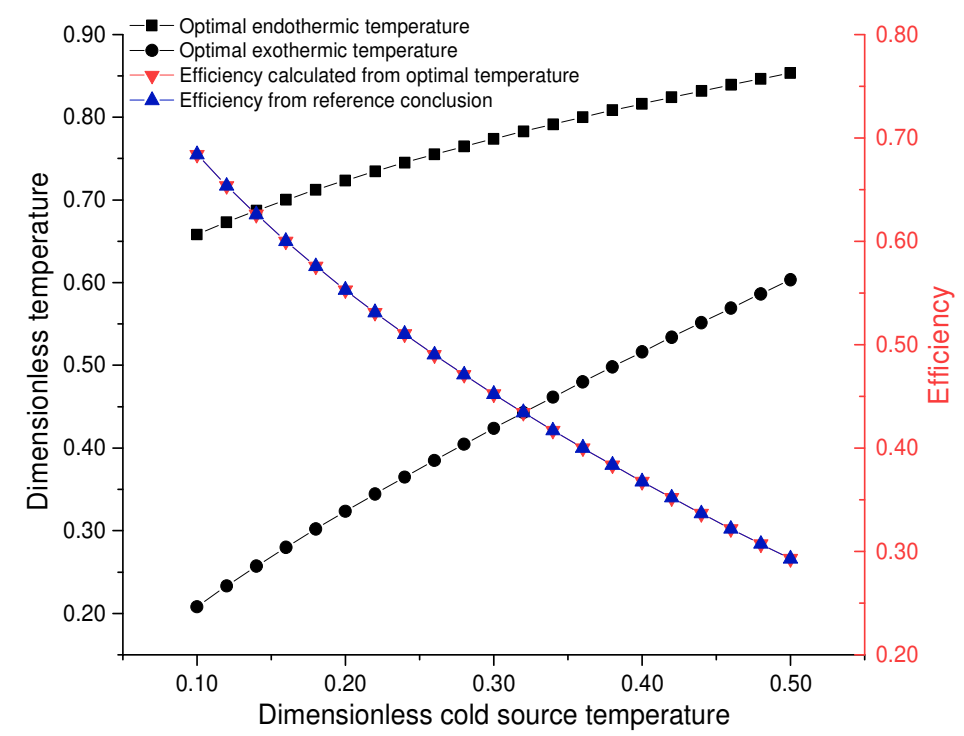

Figure 5. Variation of optimum endothermic temperatures and efficiency 


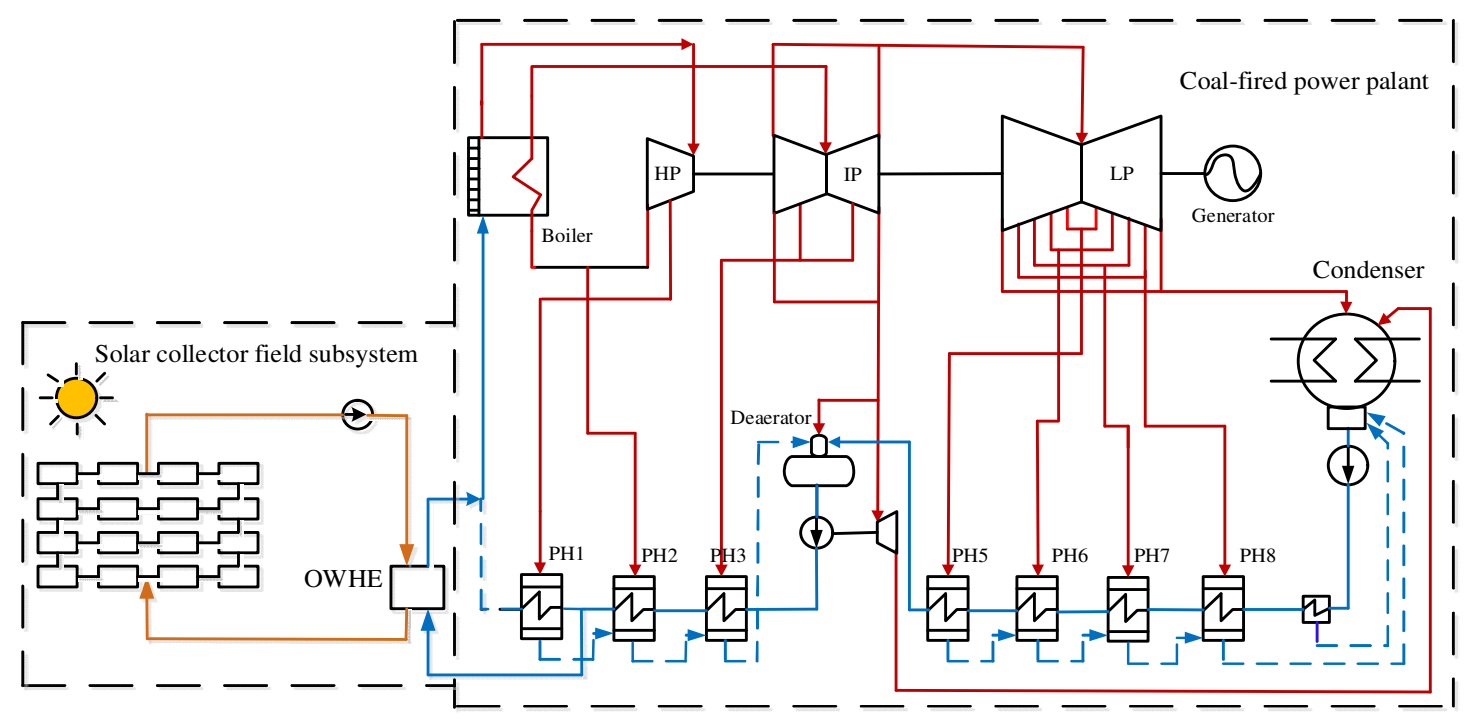

Figure. 6. Diagram of the original coal-fired power plant and the SAPG system.

Table 1. Main designed parameters of the coal-fired power plant and SPCG

\begin{tabular}{lllll}
\hline Design Parameters & Original plant & Fuel-saving SAPG & Power-boosting SAPG & Units \\
\hline Output power & 1000 & 1000 & 1057.85 & $\mathrm{MW}_{\mathrm{e}}$ \\
Feed water & $28.67 / 294.75 / 2733.43$ & $28.67 / 297.29 / 2546.29$ & $28.67 / 295.32 / 2689.32$ & $\mathrm{MPa} /{ }^{\circ} \mathrm{C} / \mathrm{t} \cdot \mathrm{h}^{-1}$ \\
Main steam & $25 / 600 / 2733.43$ & $25 / 600 / 2546.29$ & $25 / 600 / 2689.32$ & $\mathrm{MPa} /{ }^{\circ} \mathrm{C} / \mathrm{t} \cdot \mathrm{h}^{-1}$ \\
Inlet reheat steam & $4.73 / 347.13 / 2256.97$ & $4.73 / 347.10 / 2298.20$ & $4.73 / 347.03 / 2428.37$ & $\mathrm{MPa} /{ }^{\circ} \mathrm{C} / \mathrm{t} \cdot \mathrm{h}^{-1}$ \\
Outlet reheat steam & $4.25 / 600 / 2256.97$ & $4.25 / 600 / 2298.20$ & $4.25 / 600 / 2428.37$ & $\mathrm{MPa} /{ }^{\circ} \mathrm{C} / \mathrm{t} \cdot \mathrm{h}^{-1}$ \\
Solar energy heated & - & 132.68 & 132.68 & $\mathrm{MW}$ th \\
Coal consumption rate & 267.74 & 252.70 & 253.26 & $\mathrm{~g} / \mathrm{kWh}$ \\
\hline
\end{tabular}

Table 2. Comparison between the designed, calculated and the simulated results

\begin{tabular}{llll}
\hline Power plant & $\begin{array}{l}\text { Designed enthalpy drop } \\
\left(\mathrm{MW}_{\mathrm{e}}\right)\end{array}$ & $\begin{array}{l}\text { Simulated enthalpy drop } \\
\left(\mathrm{MW}_{\mathrm{e}}\right)\end{array}$ & $\begin{array}{l}\text { Calculated enthalpy } \\
\text { drop }\left(\mathrm{MW}_{\mathrm{e}}\right)\end{array}$ \\
\hline Original plant & 1011.51 & 1018.05 & 1015.90 \\
SAPG in fuel-saving mode & - & 1017.03 & 1013.48 \\
SAPG in Power-boosting mode & - & 1075.77 & 1072.12 \\
\hline
\end{tabular}

\subsection{Performance of the multi-heat-source system}

Table 3. Parameters of assumed general integrated thermodynamic system

\begin{tabular}{llll}
\hline Parameters & Value & Parameters & Value \\
\hline Dimensionless first endothermic temperature & $0.60-1.00$ & Cycle-irreversibility & 1.00 \\
Dimensionless second heat source temperature & 0.60 & $\alpha_{1} / \beta$ & 1.00 \\
Dimensionless second endothermic temperature & $0.20-0.60$ & $\alpha_{2} / \beta$ & 1.00 \\
Dimensionless cold reservoir temperature & 0.1 & $\gamma$ & 1.10 \\
Dimensionless exothermic temperature & 0.2 & $\tau$ & 1.00 \\
\hline
\end{tabular}


In an assumed general thermodynamic system with two heat sources, of which parameters are shown in Table 3, the variation of system power output with respect to the endothermic and exothermic temperatures of working fluid is shown in Figure 7. The variation of efficiency is shown in Figure 8. With the second endothermic temperature increasing, the output power increases first and then decreases. As the first endothermic temperature decreases, the system power output tends to increase, which is due to the increase in the amount of energy received per unit time from the hot reservoir despite the dropping of efficiency. System efficiency is reduced gradually when the second endothermic temperature is decreased. The maximum power is reached at the temperature structure when $\theta_{11 w}=0.62$ and $\theta_{12 w}=0.48$ and the corresponding efficiency is $65.48 \%$. The system shows different performances in the four regions around this point.

In the first region $\left(\theta_{11 w}>0.62, \theta_{12 w}<0.48\right)$, the system had the least performance with rapidly falling power output $(0.00<\phi<1.00)$ and lowest efficiency area $(0.00<\eta<68.75 \%)$. In the second region $\left(\theta_{11 w}<0.62, \theta_{12 w}<0.48\right)$, power $(0.40<\phi<1)$ and efficiency $(33.00 \%<\eta<65.48 \%)$ were slightly more stable than those of the first region but remained unsatisfactory. In these two regions, the power output and efficiency simultaneously decrease as the temperature structure away from the point. In the third region $\left(\theta_{11 w}>0.62, \theta_{12 w}>0.48\right)$, the system can reach the highest efficiency $(65.48 \%<\eta<79.80 \%)$. However, as efficiency increases, the power output inevitably decreases. When the efficiency reaches the maximum value, the power decreases to zero. In the fourth region $\left(\theta_{11 w}<0.62, \theta_{12 w}>0.48\right)$, the 
performance is also acceptable which is relatively stable and has high efficiency $(64.74 \%<\eta<67.74 \%)$ and power output $(0.92<\phi<1.00)$.

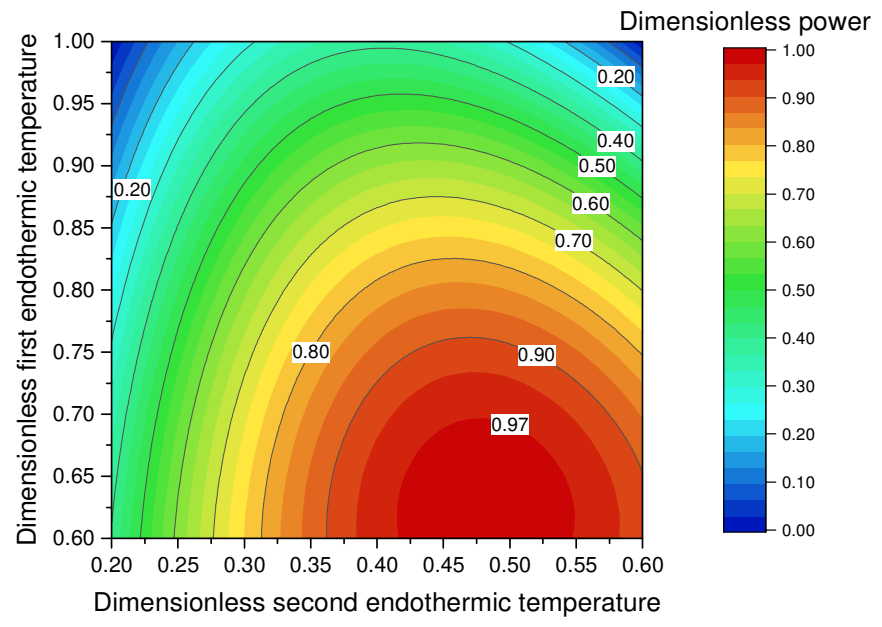

Figure 7. Map of power generation in two-heat source integrated heat engine

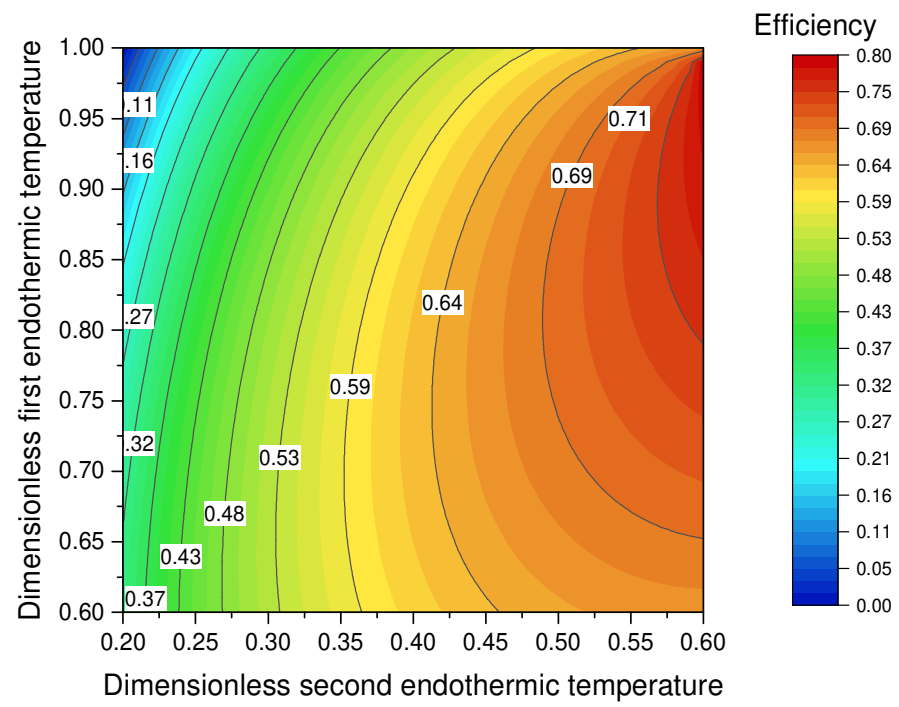

Figure 8. Map of efficiency in two-heat source integrated heat engine

\subsection{Effects of introducing an energy source}

Figure 9 shows the variation of the optimum temperature structure with respect to introduced heat source temperatures. As the dimensionless heat source temperature increases from 0.45 to 1.00 , the optimum first endothermic temperature and the second 
endothermic temperature show an increasing from 0.60 to 0.66 and from 0.40 to 0.66 , respectively. Figure 10 shows the corresponding power, efficiency and energy percentage as a function of the dimensionless second heat source temperature to maximise power. System efficiency is relatively stable and is first reduced from $66.76 \%$ to $66.13 \%$, due to the increased proportion of the second heat-source energy at a relatively lower temperature, and then increased to $68.38 \%$ as the second heat source temperature increases to its maximum. With the introduction of a second heat-source energy, the first heat-source energy consumption reduces by $10.40-50.00 \%$ at the cost of system efficiency, inevitably decreasing by a maximum of $2.25 \%$. This demonstrates the feasibility and effectiveness to use relatively low-temperature additional energy, such as solar thermal energy to reduce fossil fuel consumption and $\mathrm{CO}_{2}$ emission.

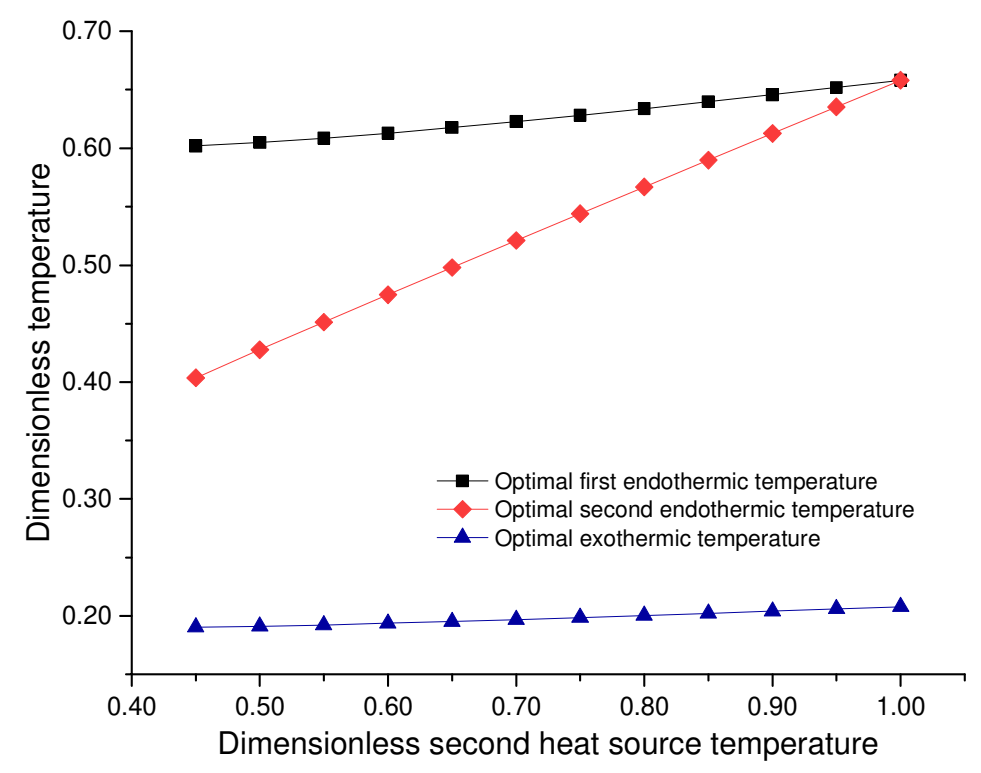

Figure 9. Effects of the second endothermic temperature on the optimum temperature distribution 


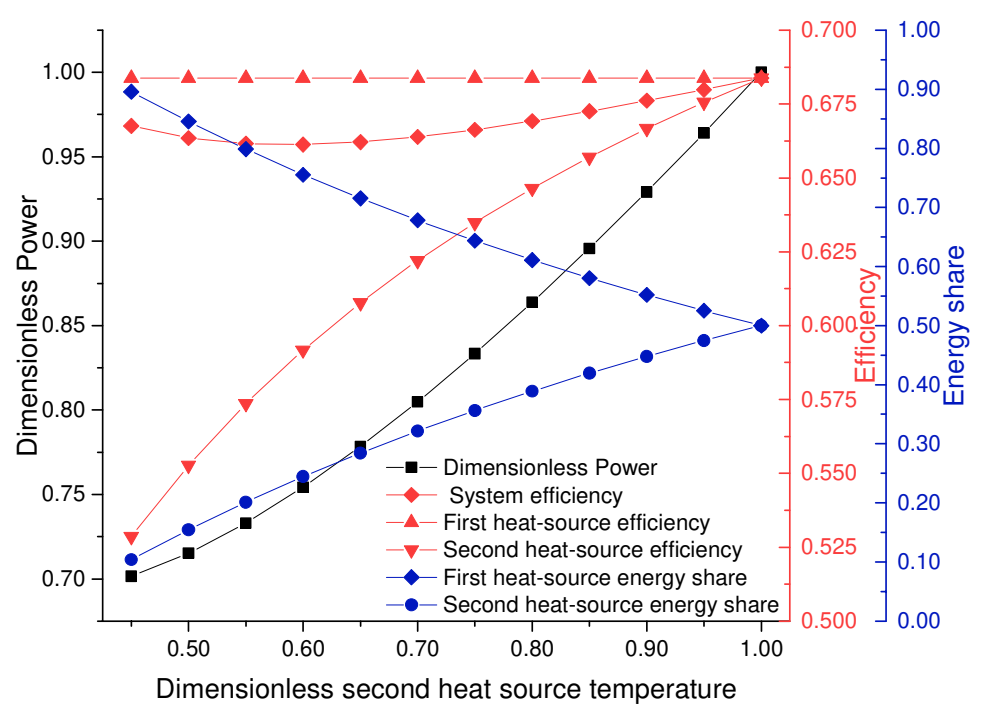

Figure 10. Effects of the second endothermic temperature on the optimum system performance

\subsection{Effects of external and internal irreversibility}

With the second hot reservoir integrated into the system, the area and heat transfer coefficient of the first heat exchanger $\left(\alpha_{1}\right)$ was assumed constant. The variation of optimum second endothermic temperature under different second heat transfer conditions is shown in Figure 11. From Figure 11, the higher external irreversibility, with less heat transfer area or lower heat transfer coefficient $\left(\frac{\alpha_{2}}{\alpha_{1}}=0.50\right)$, results in lower the optimum second endothermic temperature, which increased from 0.40 to 0.63 compared to that from 0.41 to 0.69 in lower external irreversibility condition $\left(\frac{\alpha_{2}}{\alpha_{1}}=\right.$ 2.00). The corresponding performances, including dimensionless power and energy share, are illustrated in Figure 12. As the second heat source temperature increases, the optimum power output from the integrated system also increases from 0.58 to 0.72 in higher external irreversibility condition and increases from 0.59 to 1.00 in the lower external irreversibility case. The energy consumption from the first heat source is also improved in lower external irreversibility condition, which is $12.89-33.33 \%$ lower than 
that in higher external irreversibility condition. The difference in configuration and performance is more considerable at a relatively high second heat source temperature condition, leading to the necessity of optimisation in the temperature distribution and configuration design.

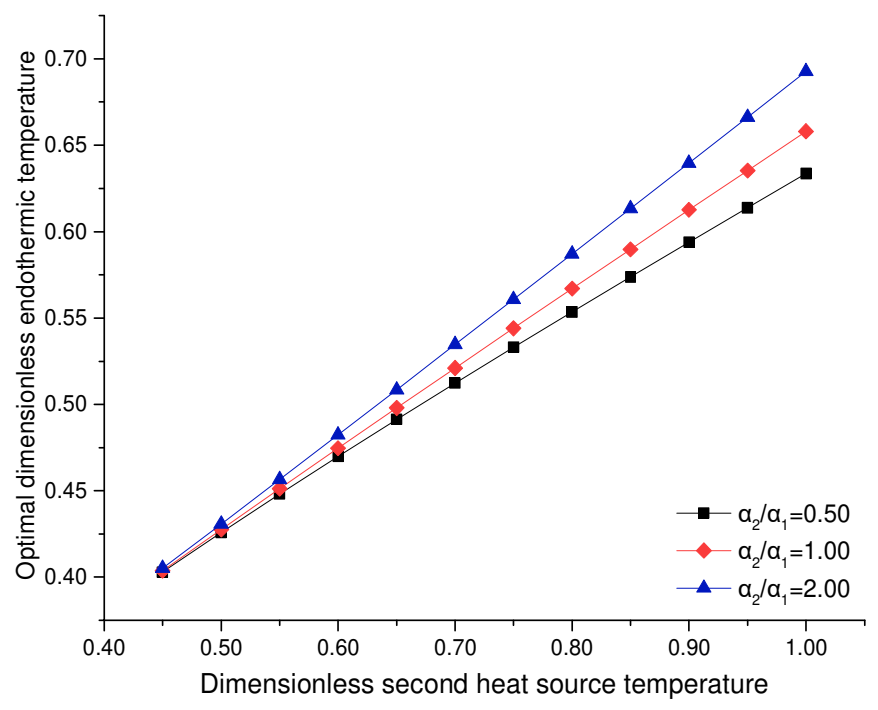

Figure 11. The optimum second endothermic temperature in different heat transfer conditions

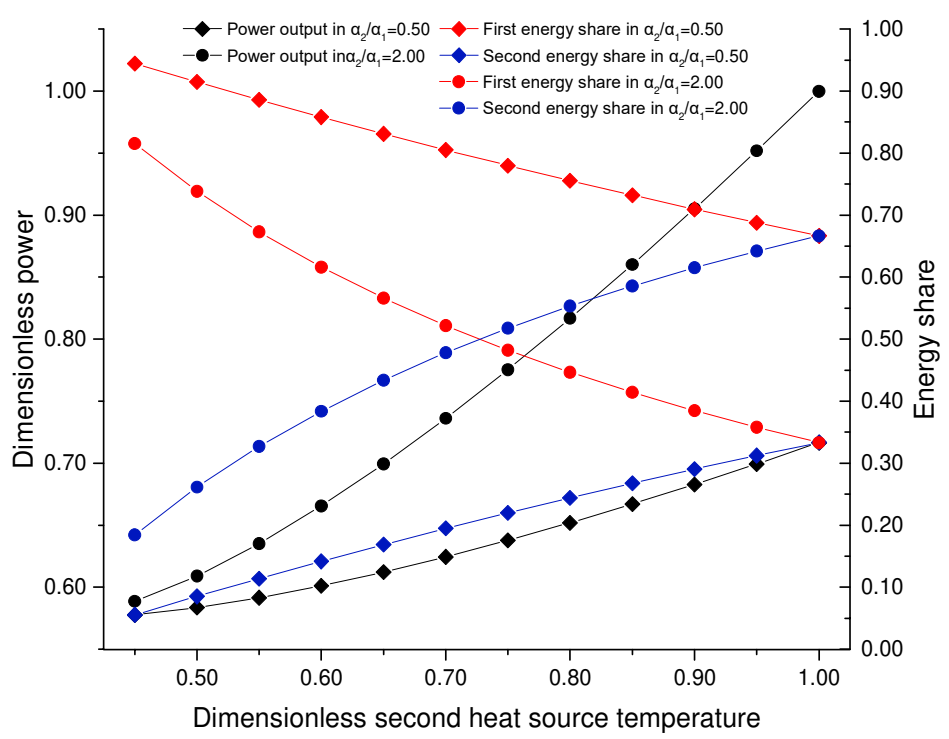

Figure 12. Optimum performance in different heat transfer conditions

Figure 13 shows the variation of second endothermic temperature in a two-heatsource integrated system at maximum power output under three different internal 
irreversibility conditions. The optimum second endothermic temperature curves show a translation, which is $0.41-0.67$ in the $R=1.10$ condition and $0.42-0.69$ in the $R=$ 1.20 condition. This variation leads to a narrowed range for the introduction of the second heat source. Figure 14 shows the variation of dimensionless power output, system efficiency and first heat-source energy share. From the figure, in the system with higher cycle-irreversibility, the optimum power output and efficiency are both decreased despite the second endothermic temperature being higher. In the $R=1.10$ and $R=1.20$ conditions, the optimum first heat-source energy consumptions are reduced by at least $8.51 \%$ and $6.52 \%$, at the cost of an efficiency reduction of a maximum of $2.29 \%$ and $2.32 \%$, respectively. The substantial reduction of first heatsource energy consumption is still achieved compared to the slight efficiency drop considering a higher cycle-irreversibility.

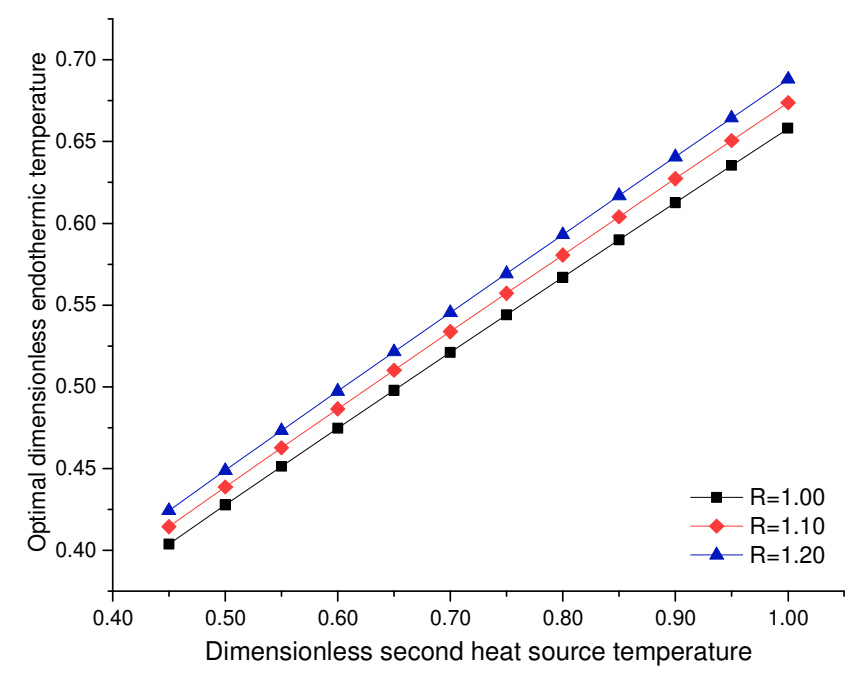

Figure 13. The optimum second endothermic temperature in different internal irreversibility 


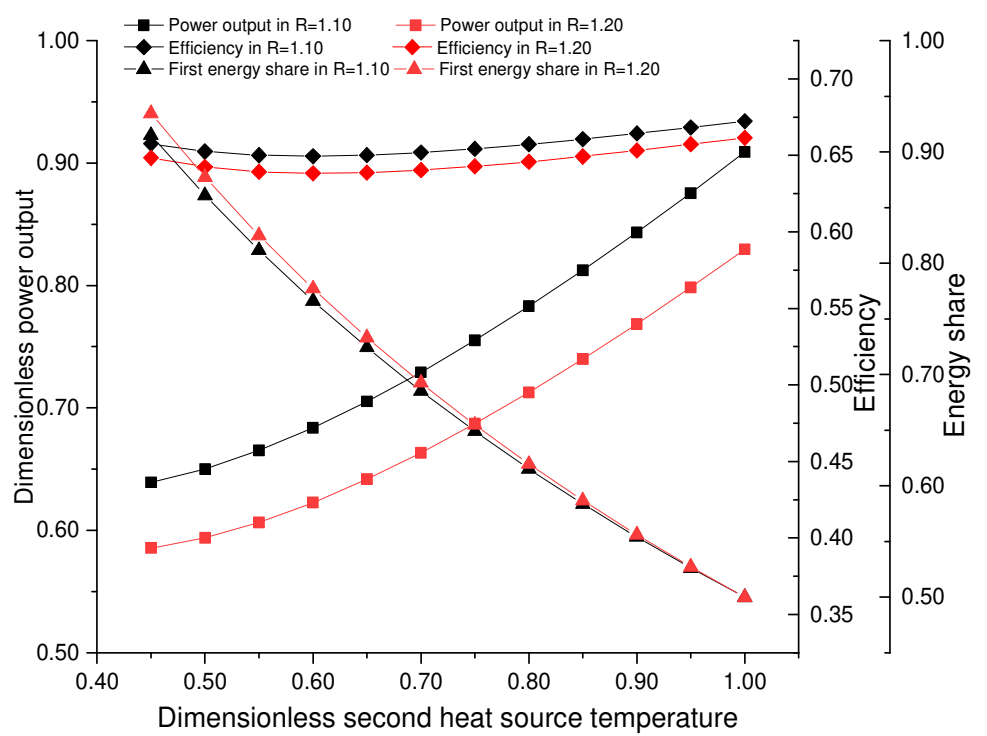

Figure 14. Optimum performance in different internal irreversibility conditions

\subsection{Temperature structure at maximum power}

Figure 15 shows the distribution of the common optimum temperature structure to obtain the maximum power in various heat and cold source conditions. Figure 16 shows the variation of corresponding power. From Figure 15, the distribution of the optimum temperature structure $\left(\theta_{11 w, m p}, \theta_{12 w, m p}\right.$, and $\left.\theta_{2 w, m p}\right)$ is clearly stratifies into three ranges, from 0.50 to 0.77 , from 0.39 to 0.77 , and from 0.05 to 0.42 , respectively. The minimum value of the dimensionless power was 0.18 , obtained at the highest cold source temperature $\left(\theta_{2}=0.30\right)$ and the lowest second heat-source temperature $\left(\theta_{12}=\right.$ 0.60) condition. For the lower temperature distribution shown in Figure 15, the power output and system efficiency both decrease, while the power output decreases and system efficiency increases in higher temperature distribution (analysed in Figure 7). Thus, Figure 15 and 16 illustrate the configuration and performance boundary of this integrated system under different heat and cold source conditions. 


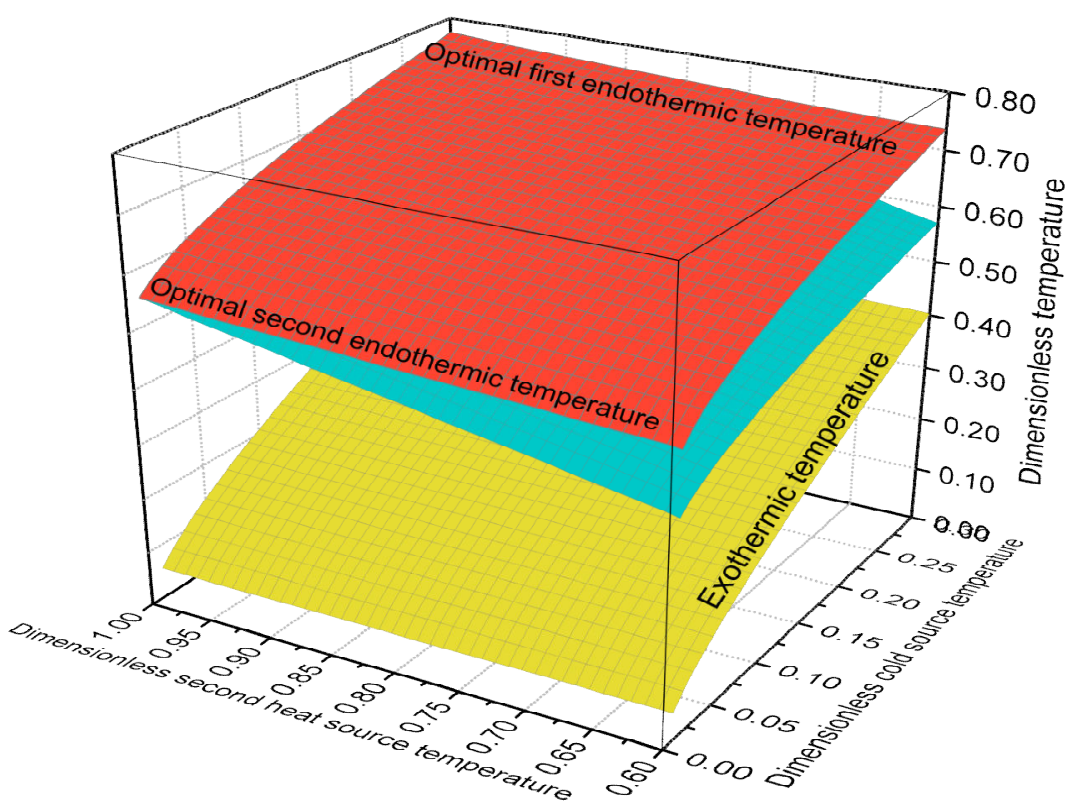

Figure 15. Distribution of the optimum endothermic and exothermic temperatures

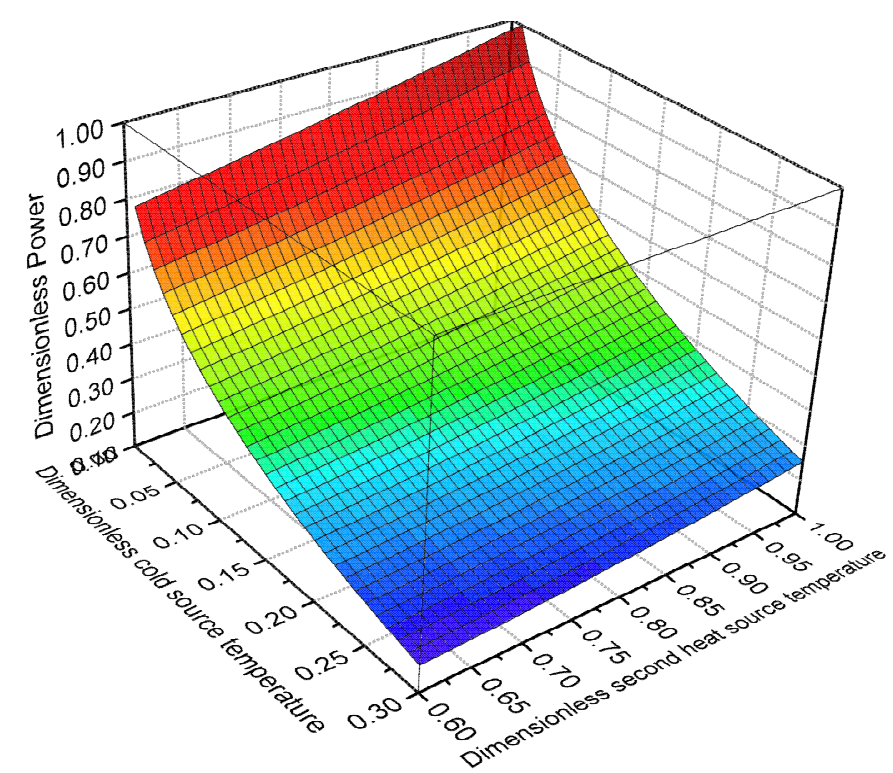

Figure 16. Distribution of the optimum power output in the two-heat source-integrated heat engine

\section{Examples of application}

In this section, the developed method was applied to four individual cases of

421 SAPG to find the reasonable position of introducing solar energy, including a 1000

$\mathrm{MW}_{\mathrm{e}}$ STCG operating in fuel-saving mode [18] as shown in Figure 17, a $1000 \mathrm{MW}_{\mathrm{e}}$ 

operating in the power-boosting mode [34], as shown in Figure 20.

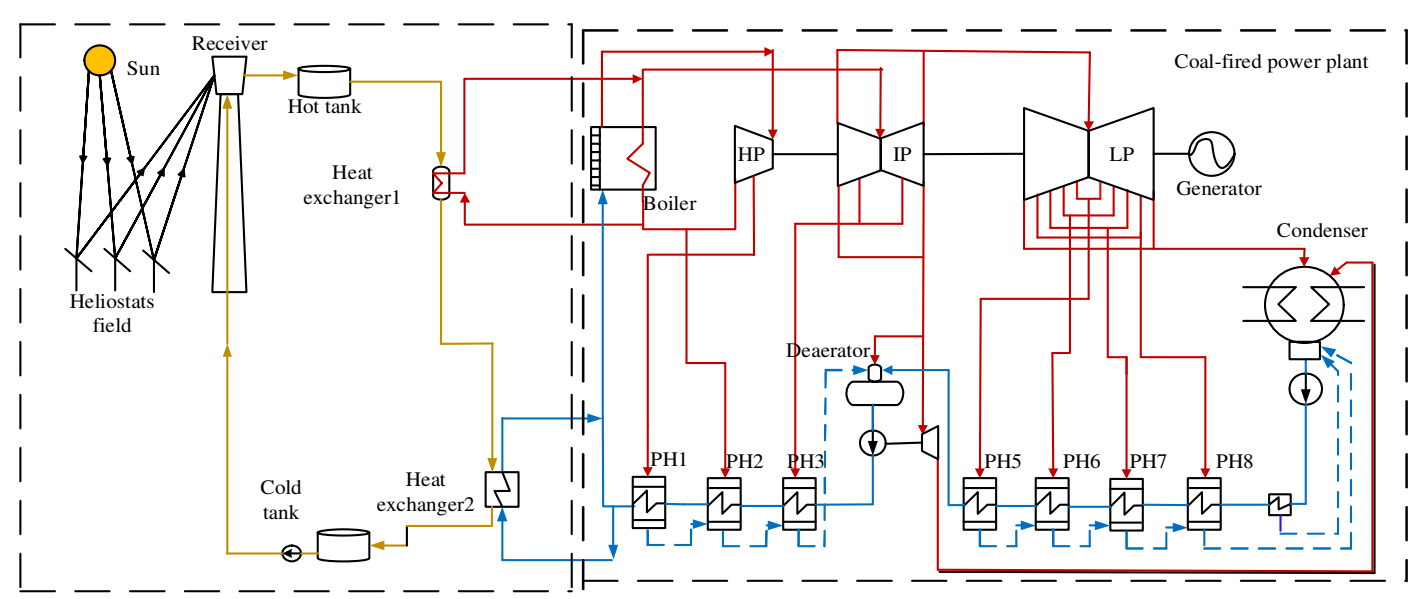

Figure 17. Diagrams of the $1000 \mathrm{MW}_{\mathrm{e}} \mathrm{STCG}$ in fuel-saving mode

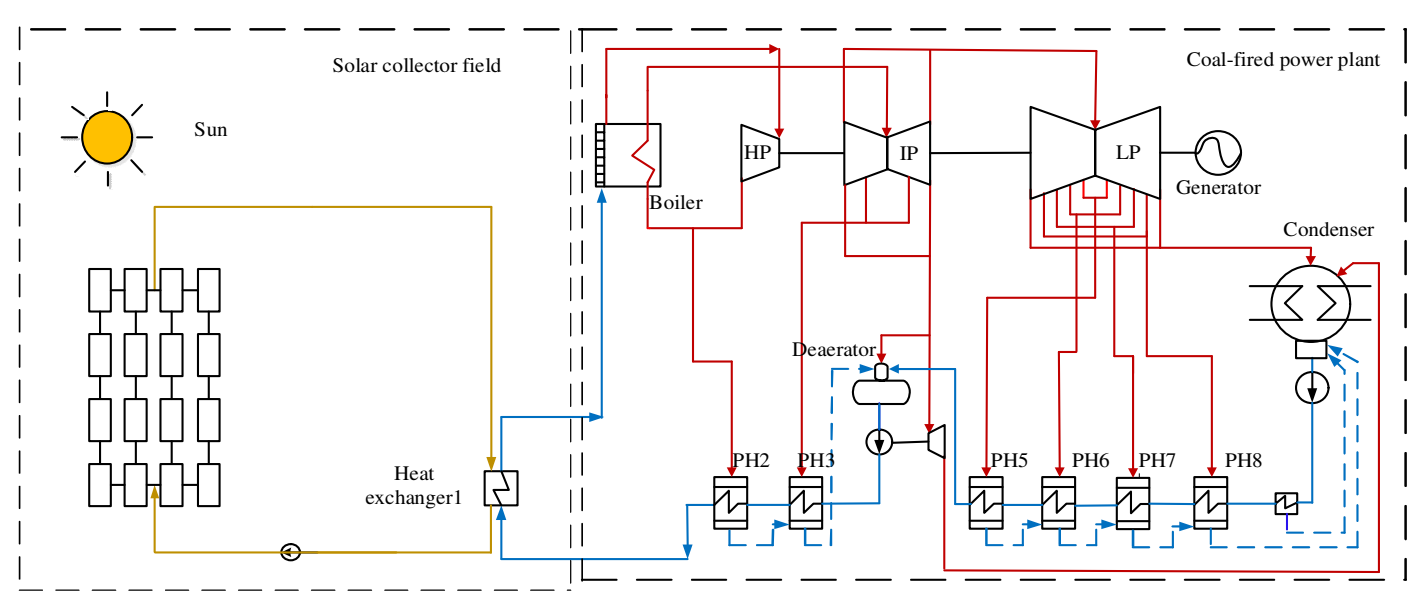

Figure 18. Diagrams of the $1000 \mathrm{MW}_{\mathrm{e}} \mathrm{SPCG}$ in the power-boosting mode

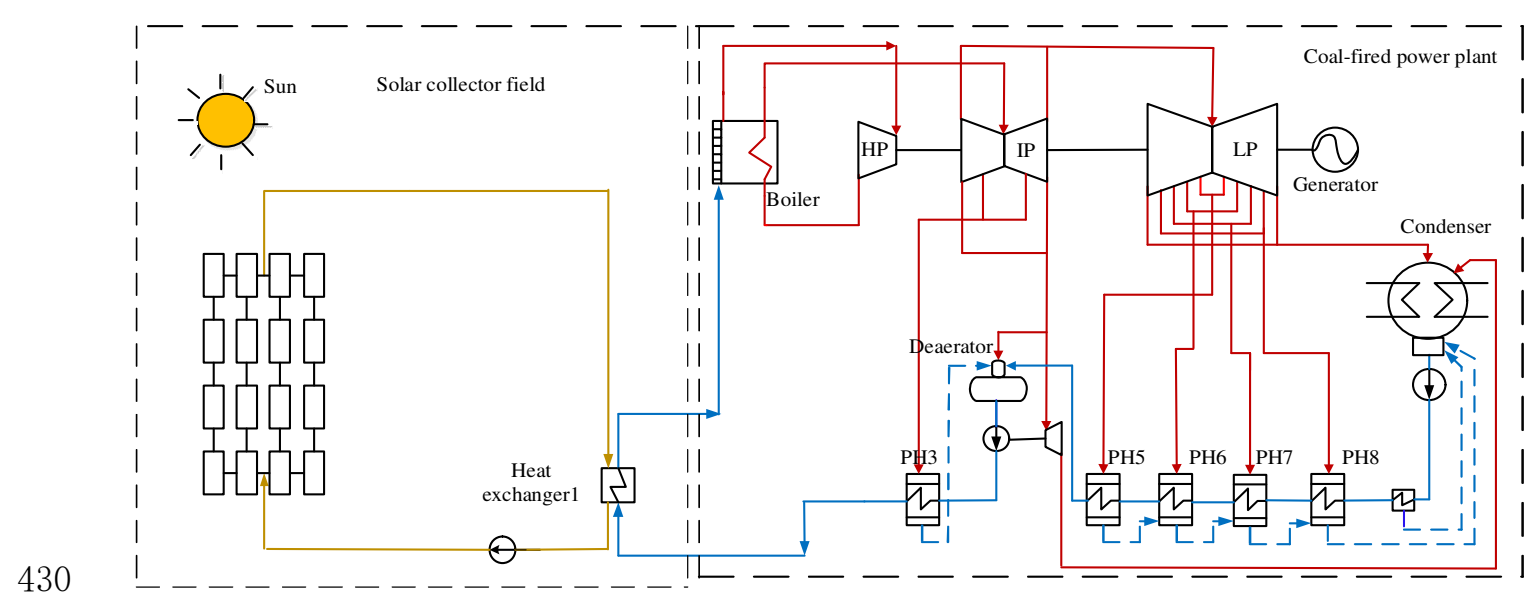




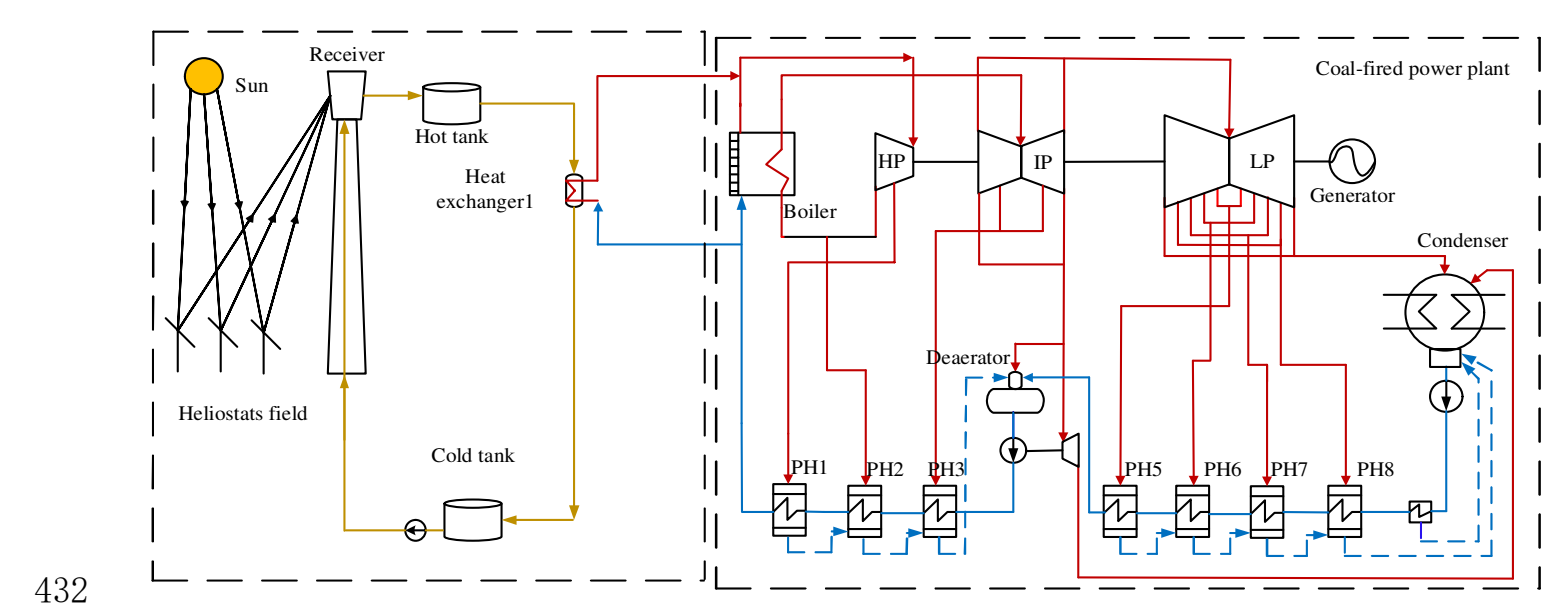

Figure 20. Diagrams of the $660 \mathrm{MW}_{\mathrm{e}} \mathrm{STCG}$ in power-boosting mode

434 Table 4. Main designed parameters of the four cases

\begin{tabular}{lllll}
\hline Parameters & Original plant & Fuel-saving mode & Power-boosting mode & Units \\
\hline Integrated position & - & Reheat steam and feedwater & Feedwater in PH1 & - \\
Solar energy source & - & Solar tower & Parabolic trough & - \\
Output power & 1000 & 1000 & 1057.85 & $\mathrm{MW}_{\mathrm{e}}$ \\
Feed water & $28.67 / 294.75 / 2733.43$ & $28.67 / 294.77 / 2733.43$ & $28.67 / 297.29 / 2546.29$ & $\mathrm{MPa} /{ }^{\circ} \mathrm{C} / \mathrm{t} \cdot \mathrm{h}^{-1}$ \\
Main steam & $25 / 600 / 2733.43$ & $25 / 600 / 2546.29$ & $25 / 600 / 2546.29$ & $\mathrm{MPa} /{ }^{\circ} \mathrm{C} / \mathrm{t} \cdot \mathrm{h}^{-1}$ \\
Inlet reheat steam & $4.73 / 347.13 / 2256.97$ & $4.73 / 467.65 / 2273.37$ & $4.73 / 347.10 / 2298.20$ & $\mathrm{MPa} /{ }^{\circ} \mathrm{C} / \mathrm{t} \cdot \mathrm{h}^{-1}$ \\
Outlet reheat steam & $4.25 / 600 / 2256.97$ & $4.25 / 600 / 2273.37$ & $4.25 / 600 / 2298.20$ & $\mathrm{MPa} /{ }^{\circ} \mathrm{C} / \mathrm{t} \cdot \mathrm{h}^{-1}$ \\
Solar thermal energy & - & 240.52 & 132.68 & $\mathrm{MW} \mathrm{e}$ \\
Coal consumption rate & 267.74 & 235.26 & 252.70 & $\mathrm{~g} / \mathrm{kWh}$ \\
\hline Integrated position & - & Feedwater in PH1 and PH2 & Superheated steam & - \\
Solar energy source & - & Parabolic trough & Solar tower & - \\
Output power & 660 & 660 & 704.59 & $\mathrm{MW}$ \\
Feed water & $26.67 / 274.73 / 1836.49$ & $26.67 / 274.73 / 1641.43$ & $26.67 / 274.73 / 1954.90$ & $\mathrm{MPa} /{ }^{\circ} \mathrm{C} / \mathrm{t} \cdot \mathrm{h}^{-1}$ \\
Main steam & $24.2 / 566 / 1836.49$ & $24.2 / 566 / 1641.43$ & $24.2 / 566 / 1954.90$ & $\mathrm{MPa} /{ }^{\circ} \mathrm{C} / \mathrm{t} \cdot \mathrm{h}^{-1}$ \\
Inlet reheat steam & $4.40 / 311.83 / 1547.55$ & $4.40 / 311.83 / 1609.93$ & $4.40 / 311.83 / 1649.35$ & $\mathrm{MPa} /{ }^{\circ} \mathrm{C} / \mathrm{t} \cdot \mathrm{h}^{-1}$ \\
Outlet reheat steam & $3.92 / 566 / 1547.55$ & $3.92 / 566 / 1609.93$ & $3.92 / 566 / 1649.35$ & $\mathrm{MPa} /{ }^{\circ} \mathrm{C} / \mathrm{t} \cdot \mathrm{h}^{-1}$ \\
Solar thermal energy & - & 138.10 & 89.56 & $\mathrm{MW} \mathrm{e}$ \\
Coal consumption rate & 274.66 & 253.17 & 257.54 & $\mathrm{~g} / \mathrm{kWh}$ \\
\hline
\end{tabular}

436 Table 5. Comparison between the calculated results and the simulated results

\begin{tabular}{|c|c|c|c|c|c|c|}
\hline \multirow[b]{2}{*}{ Fuel-saving mode } & \multicolumn{3}{|l|}{$1000 \mathrm{MW}$} & \multicolumn{3}{|l|}{ 660MW } \\
\hline & $\begin{array}{l}\text { Original } \\
\text { plant }\end{array}$ & $\begin{array}{l}\text { Before } \\
\text { optimisation }\end{array}$ & $\begin{array}{l}\text { After } \\
\text { optimisation }\end{array}$ & $\begin{array}{l}\text { Original } \\
\text { plant }\end{array}$ & $\begin{array}{l}\text { Before } \\
\text { optimisation }\end{array}$ & $\begin{array}{l}\text { After } \\
\text { optimisation }\end{array}$ \\
\hline Coal fuel energy ( $\left.\mathrm{MW}_{\mathrm{th}}\right)$ & 2042.61 & 1808.60 & 1656.19 & 1383.57 & 1275.32 & 1050.24 \\
\hline Share of chemical energy (\%) & 100 & 88.16 & 78.15 & 100 & 90.23 & 70.67 \\
\hline Solar energy inlet temperature $\left({ }^{\circ} \mathrm{C}\right)$ & - & 614.51 & 538.71 & - & 514.25 & 494.85 \\
\hline Introduced solar energy $\left(\mathrm{MW}_{\mathrm{th}}\right)$ & 0 & 242.95 & 462.98 & 0 & 138.10 & 435.90 \\
\hline
\end{tabular}




\begin{tabular}{lllllll} 
Share of solar energy $(\%)$ & 0 & 11.84 & 21.85 & 0 & 9.77 & 29.33 \\
System power output $\left(\mathrm{MW}_{\mathrm{e}}\right)$ & 1018.05 & 1018.05 & 1018.05 & 671.80 & 671.80 & 671.80 \\
Thermal efficiency $(\%)$ & 49.84 & 49.62 & 48.04 & 48.56 & 47.53 & 45.20 \\
Coal fuel saved percentage $(\%)$ & - & 11.46 & 18.92 & - & 7.82 & 24.09 \\
\hline Power boosting mode & & & & & \\
\hline Coal fuel energy $\left(\mathrm{MW}_{\mathrm{th}}\right)$ & 2042.61 & 2042.61 & 2042.61 & 1383.57 & 1383.57 & 1383.57 \\
Share of chemical energy $(\%)$ & 100 & 93.90 & 87.73 & 100 & 93.92 & 84.35 \\
Solar energy inlet temperature $\left({ }^{\circ} \mathrm{C}\right)$ & - & 550.10 & 494.95 & - & 664.15 & 526.91 \\
Introduced solar energy $(\mathrm{MW}$ th) & 0 & 132.68 & 285.55 & 0 & 89.55 & 256.64 \\
Share of solar energy $(\%)$ & 0 & 6.10 & 12.27 & 0 & 6.08 & 15.65 \\
System power output $(\mathrm{MW})$ & 1018.05 & 1075.77 & 1091.3 & 671.80 & 704.59 & 740.15 \\
Thermal efficiency $(\%)$ & 49.84 & 49.45 & 46.87 & 48.56 & 47.83 & 45.13 \\
Power boosted percentage $(\%)$ & - & 5.67 & 7.20 & - & 4.88 & 10.17 \\
\hline
\end{tabular}
input temperatures at the maximum power in 1000 and $660 \mathrm{MW}_{\mathrm{e}} \mathrm{STCG}$ systems were 538.71 K and 526.91 K, respectively. The temperatures in the SPCG systems were 494.95 $\mathrm{K}$ and $494.85 \mathrm{~K}$ in the $1000 \mathrm{MW}_{\mathrm{e}}$ and $660 \mathrm{MW}_{\mathrm{e}}$ capacity plants, respectively. Thus, in cases 1 and 4, the STCG systems, the optimum introduction point of solar energy was above PH1. In cases 2 and 3, the SAPG systems, the introduction point above PH2 can be considered. The temperature required in SAPG based on solar tower subsystem was higher than that in parabolic collectors, but the capacity of the plant has only a small influence on the integrating position. At the optimum temperature, coal consumption is effectively reduced by $12.27-29.33 \%$ due to the introduction of solar energy, with the system efficiency reducing by $1.80-3.43 \%$. In the fuel-saving mode, a further $7.46 \%$ of coal was saved in the new $1000 \mathrm{MW}_{\mathrm{e}}$ STCG compared with the original STCG, and dramatically $16.27 \%$ of coal fuel can be further saved in the 660

$451 \mathrm{MW}_{\mathrm{e}} \mathrm{SPCG}$ system. In the power-boosting mode, the system boosted power output can be increased by $1.53 \%$ in the $1000 \mathrm{MW}_{\mathrm{e}} \mathrm{SPCG}$ and by $5.29 \%$ in $660 \mathrm{MW}_{\mathrm{e}} \mathrm{STCG}$. 
These temperature points are the low temperatures boundary of the preferred regions in these systems. When the second endothermic temperatures of the working fluid are lower than the temperature points, the power output and efficiency are both reduced. When the second endothermic temperatures of the working fluid are higher than the temperature points, higher efficiency can be obtained. However, the power output inevitably decreases to zero. This calculation was based on a $R=1.00$ condition. Considering the effects of internal irreversibility, the optimum introduction point should be at higher temperature in practice.

\section{Conclusions}

In the present work, a generalised multi-heat-source integrated system model was developed based on finite-time thermodynamics to explore a common method to integrate different energy sources. The conclusions are summarised as follows:

1. The theoretical expressions for optimum integration method of a generalised multi-heat-source integrated system are explored with dimensionless parameters, considering the external and internal irreversibility. The dimensionless optimum temperature structure obtained from one system can be applied to any specific system with similar heat exchange conditions and dimensionless temperature distribution to maximise the power output.

2. The distribution of power output and efficiency indicated that a system with two heat-sources performs differently in four regions and it depends on the endothermic and exothermic temperatures of working fluid. The highest efficiency and power output are impossible to be achieved under any schemes. However, stable and relatively higher 
power output and efficiency can be maintained in the fourth region.

3. An introduction of additional energy such as solar thermal is effective to reduce first heat-source energy consumption, and its $\mathrm{CO}_{2}$ emissions at the cost of system efficiency slightly decreasing. The integrated system performance is more sensitive to external irreversibility at higher second heat-source temperature condition, results in a narrowed optimum integration region and diminished benefits.

4. The distribution diagram of the optimum thermodynamic structure under different temperatures of the second heat and cold reservoir was drawn, illustrating the configuration and performance of this integrated system.

5. Four individual SAPG systems were considered to determine the optimum solar energy input temperature and its performance boundary, showing feasibility and potential for application on other multi-heat-source integration systems.

\section{Acknowledgements}

The research work is supported by the China National Natural Science Foundation (No. 51776063), National Basic Research Program of China (2015CB251505), Science Fund for Creative Research Groups of the National Natural Science Foundation of China (No. 51821004), the Fundamental Research Funds for the Central Universities (2019QN010) and China Scholarship Council with support from Cranfield University as host institute.

\section{Nomenclature}




\begin{tabular}{|c|c|c|}
\hline Symbol & Description & Unit \\
\hline$\alpha_{i}$ & $\begin{array}{l}\text { Heat transfer areas and the total heat transfer coefficients for the } i_{t h} \\
\text { endothermic process }\end{array}$ & $\mathrm{W} / \mathrm{K}$ \\
\hline$A_{1 \mathrm{i}}$ & Heat transfer area for $i_{t h}$ endothermic process & $\mathrm{m}^{2}$ \\
\hline$k_{1 \mathrm{i}}$ & Total heat transfer coefficient for the $i_{t h}$ endothermic process & $\mathrm{W} /\left(\mathrm{m}^{2} \cdot \mathrm{K}\right)$ \\
\hline$A_{2}$ & Heat transfer area for the exothermic process & $\mathrm{m}^{2}$ \\
\hline$k_{2}$ & Total heat transfer coefficient for the exothermic process & $\mathrm{W} /\left(\mathrm{m}^{2} \cdot \mathrm{K}\right)$ \\
\hline$\beta$ & $\begin{array}{c}\text { Heat transfer areas and the total heat transfer coefficients for the exothermic } \\
\text { process }\end{array}$ & $\mathrm{W} / \mathrm{K}$ \\
\hline$\tau_{1 i}$ & Time ratio of the $i_{t h}$ endothermic process to the first endothermic process & - \\
\hline$\dot{Q_{1 \imath}}$ & Heat transfer rate in the $i_{t h}$ endothermic process & $\mathrm{W}$ \\
\hline$\dot{Q_{2}}$ & Heat transfer rate in the exothermic process & $\mathrm{W}$ \\
\hline$\theta_{1 i}$ & Dimensionless temperature of $i_{t h}$ heat source & - \\
\hline$\theta_{1 i w}$ & Dimensionless temperature of working fluid in the $i_{t h}$ endothermic process & - \\
\hline$\theta_{2}$ & Dimensionless temperature of the cold reservoir & - \\
\hline$T_{11}$ & Temperature of the first heat source & $\mathrm{K}$ \\
\hline$T_{11 w}$ & Average temperature of working fluid in the first endothermic process & $\mathrm{K}$ \\
\hline$T_{12}$ & Temperature of the second heat source & $\mathrm{K}$ \\
\hline$T_{12 w}$ & Average temperature of working fluid in the second endothermic process & $\mathrm{K}$ \\
\hline$T_{2 w}$ & Average temperature of working fluid in the exothermic process & $\mathrm{K}$ \\
\hline$T_{2}$ & Temperature of the cold reservoir & $\mathrm{K}$ \\
\hline$T_{1 i w, m p}$ & $\begin{array}{c}\text { Temperature of working fluid in the } i_{t h} \text { endothermic process at maximum } \\
\text { power }\end{array}$ & $\mathrm{K}$ \\
\hline$T_{2 w, m p}$ & Temperature of working fluid in the exothermic process at maximum power & $\mathrm{K}$ \\
\hline$\lambda_{i}$ & Energy share of the $i_{t h}$ heat source & - \\
\hline$R$ & Cycle-irreversibility & - \\
\hline$S_{\mathrm{i}}$ & Specific entropy of working fluid at the status point $i$. & $\mathrm{kJ} / \mathrm{kg}$ \\
\hline$\tau$ & Time ratio of the two endothermic processes & - \\
\hline
\end{tabular}


[1] Hoel M, Kverndokk S. Depletion of fossil fuels and the impacts of global warming. Resource and energy economics, 1996, 18(2): 115-136.

[2] Wang B, Wang Q, Wei Y M, et al. Role of renewable energy in China's energy security and climate change mitigation: An index decomposition analysis. Renewable and sustainable energy reviews, 2018, 90: 187-194.

[3] Yuksel Y E, Ozturk M, Dincer I. Thermodynamic performance assessment of a novel environmentally-benign solar energy based integrated system. Energy Conversion and Management, 2016, 119: 109-120.

[4] Zoschak RJ, Wu SF. Studies of the direct input of solar energy to a fossil-fueled central station steam power plant. Sol Energy 1975;17(5):297e305.

[5] Hu E, Yang Y, Nishimura A, Yilmaz F, Kouzani A. Solar thermal aided power generation. Applied Energy. 2010;87:2881-5.

[6] Elia J A, Baliban R C, Xiao X, et al. Optimum energy supply network determination and life cycle analysis for hybrid coal, biomass, and natural gas to liquid (CBGTL) plants using carbon-based hydrogen production. Computers \& Chemical Engineering, 2011, 35(8): 1399-1430.

[7] Suman S. Hybrid nuclear-renewable energy systems: a review. Journal of Cleaner Production, 2018, 181: 166-177.

[8] Radcliff T D, Biederman B P, Brasz J J. Cascaded organic rankine cycles for waste heat utilization: U.S. Patent 7,942,001. 2011-5-17.

[9] Yang Y, Yan Q, Zhai R, Kouzani A, Hu E. An efficient way to use medium-or-low temperature solar heat for power generation - integration into conventional power 
plant. Applied Thermal Engineering. 2011;31:157-62.

522

[10]Powell K M, Rashid K, Ellingwood K, et al. Hybrid concentrated solar thermal power systems: A review. Renewable and Sustainable Energy Reviews, 2017, 80: 215-237.

[11]Popov D. An option for solar thermal repowering of fossil fuel fired power plants. Solar Energy, 2011, 85(2): 344-349.

[12]Bakos G C, Tsechelidou C. Solar aided power generation of a 300 MW lignite fired power plant combined with line-focus parabolic trough collectors field. Renewable Energy, 2013, 60: 540-547.

[13]Rech S, Lazzaretto A, Grigolon E. Optimum integration of concentrating solar technologies in a real coal-fired power plant for fuel saving. Energy Conversion and Management. 2018;178:299-310.

[14]Qin J, Hu E, Nathan GJ. The performance of a Solar Aided Power Generation plant with diverse "configuration-operation" combinations. Energy Conversion and Management. 2016;124:155-67.

[15] Wu J, Hou H, Yang Y. The optimization of integration modes in solar aided power generation (SAPG) system. Energy Conversion and Management. 2016;126:77489.

[16] Wu J, Hou H, Hu E, et al. Performance improvement of coal-fired power generation system integrating solar to preheat feedwater and reheated steam. Solar Energy, 2018, 163: 461-470.

[17]Wang J, Duan L, Yang Y, Yang Z, Yang L. Study on the general system integration 
optimization method of the solar aided coal-fired power generation system. Energy. 2019;169:660-73.

[18]Zhu Y, Zhai R, Peng H, Yang Y. Exergy destruction analysis of solar tower aided coal-fired power generation system using exergy and advanced exergetic methods. Applied Thermal Engineering. 2016;108:339-46.

[25]Durmayaz A, Sogut O S, Sahin B, et al. Optimization of thermal systems based on 
[26]Wu C, Kiang R L. Finite-time thermodynamic analysis of a Carnot engine with internal irreversibility. Energy, 1992, 17(12): 1173-1178.

[27]Mousapour A, Hajipour A, Rashidi M M, et al. Performance evaluation of an irreversible Miller cycle comparing FTT (finite-time thermodynamics) analysis and ANN (artificial neural network) prediction. Energy, 2016, 94: 100-109.

[28]Nazemzadegan M R, Kasaeian A, Toghyani S, et al. Multi-objective optimization

[29]Lu X, Yao W, Wang C, et al. Exergy analysis of a lunar based solar thermal power system with finite-time thermodynamics. Energy Procedia, 2019, 158: 792-796.

[30] Yasunaga T, Ikegami Y. Finite-time thermodynamic model for evaluating heat engines in ocean thermal energy conversion. Entropy, 2020, 22(2): 211.

[31]Mehrpooya M, Taromi M, Ghorbani B. Thermo-economic assessment and retrofitting of an existing electrical power plant with solar energy under different operational modes and part load conditions. Energy Reports, 2019, 5: 1137-1150.

[32]Zhai R, Liu H, Li C, et al. Analysis of a solar-aided coal-fired power generation system based on thermo-economic structural theory. Energy, 2016, 102: 375-387.

[33]Zhai R, Yu H, Chen Y, et al. Integration of the $660 \mathrm{MW}$ supercritical steam cycle with the NH3-based $\mathrm{CO}_{2}$ capture process: System integration mechanism and general correlation of energy penalty. International Journal of Greenhouse Gas Control, 2018, 72: 117-129. 

tower aided coal-fired power plant for different solar multiples with thermal energy storage. Energy, 2018, 163: 956-968. 